\title{
Exterior constitutivo e interior transitivo: os componentes identitários do Brasil e seus outros no pensamento de Eduardo Prado
}

\author{
CARLOS HENRIQUE ARMANI*
}

\begin{abstract}
Resumo: Pretendo apresentar algumas reflexões sobre o pensamento de Eduardo Prado relativos à identidade nacional, e como o autor entende e constrói a relação entre exterior constitutivo e interior transitivo no caso da identidade nacional brasileira, o que envolve, em seu pensamento, formas de pensar não somente uma identidade brasileira, mas também uma identidade européia e uma identidade americana.
\end{abstract}

Abstract: I intend to show some reflections about the thought of Eduardo Prado concerning the national identity, and how the author understands and constructs the relation between constitutive outside and transitive inside in the case of Brazilian national identity, which involves in his thought, ways to think not just a Brazilian identity, but also an American and an European identity.

Palavras-chave: História das idéias. Identidade nacional. Eduardo Prado.

Key words: History of ideas. National identity. Eduardo Prado.

O pensamento que envolve a construção das retóricas acerca da identidade nacional tem sido marcado por uma certa relação binária entre o ser e o não-ser, a qual delimita o "nós" enquanto pertencimento, do "outro" como um corpo estranho em relação ao ser nacional que se pretende distinguir. Desse modo, certos discursos da nação giram em torno de um ser $^{1}$ - o que supostamente a define como algo único - e um não-ser - não como sinônimo do nada, mas sim como o "outro" (ou os outros), do qual se procura diferenciar. É para essa relação do ser com o não-ser na retórica nacionalista

* Doutorando em História na PUCRS; bolsista da CAPES.

E-mail: chapoa@brturbo.com.br.

1 Uso a expressão em itálico, posto que não estou preconizando, via investigação do pensamento de Prado, uma ontologia da nação.

Estudos Ibero-Americanos. PUCRS, v. XXXI, n. 1, p. 167-180, junho 2005 
que direcionei este artigo, tomando como recorte empírico o pensamento de um intelectual brasileiro de finais do século XIX: Eduardo Prado. O trabalho foi dividido em três partes: na primeira, procuro investigar os chamados exteriores constitutivos do Brasil, numa direção em que o exterior tem apenas um sentido de regulação do eu nacional como negação: o que o Brasil não é. Na segunda parte, apresento certas qualidades atribuídas por Prado em relação ao Brasil republicano, que constituem uma espécie de outro do Brasil, seu interior transitivo. Na última parte, faço algumas ponderações acerca dos limites e possibilidades de pensar o pensamento de Eduardo Prado nos marcos da ideologia.

Eduardo Prado, que nasceu em 1860 e faleceu em 1901, viveu num período bastante conturbado não somente da política brasileira, que passava por um processo de transição da Monarquia para a República, mas do próprio mundo intelectual de fim de século. Politicamente vinculado à monarquia, sua obra mais conhecida, $A$ ilusão americana ${ }^{2}$, denunciou a aproximação que o Brasil estava inaugurando com os Estados Unidos na virada do século, quando da proclamação da República no Brasil, em 1889. Segundo Prado, como o próprio título de sua obra sugere, tratava-se de uma ilusão, de uma visão deturpada dos republicanos brasileiros em relação aos Estados Unidos e à república como forma de governo implementada no Brasil. Seu livro tem como fio condutor a denúncia dessa relação, o que lhe custou a censura da obra num período imediato à sua publicação. ${ }^{3}$

É claro que a velocidade das mudanças históricas no campo político não serve como baliza para pensar o plano das cosmovisões. Se Prado "foi ferido no cerne da sua alma, no seu ideal político e no seu ideal religioso, porque testemunhava a substituição do Brasil monárquico e católico por uma república anticatólica", ${ }_{4}$ é possível imaginar que seu libelo contra a República não estava circunscrito

2 PRADO, Eduardo. A ilusão americana. São Paulo: Brasiliense, 1961.

3 Na própria obra, Prado apresenta a relação dos fatos: "No dia 4 de dezembro de 1893 foi posto este livro à venda nas livrarias de São Paulo. Vendidos todos os exemplares prontos nesse dia, foi às livrarias o chefe de polícia e proibiu a venda. Na manhã seguinte, a tipografia em que foi impresso o livro amanheceu cercada por uma força de cavalaria, e compareceram à porta da oficina um delegado de polícia acompanhado de um burro que puxava uma carroça. $\mathrm{O}$ delegado entrou pela oficina e mandou ajuntar todos os exemplares do livro, mandando-o amontoar na carroça. O burro e o delegado levaram o livro para a repartição da polícia”. Ver: PRADO, op. cit., p. 191. Note-se a acidez da narrativa de Prado, em que o delegado e o burro tornam-se sujeitos da mesma ação.

4 CASASANTA, Mario. Apresentação. In: PRADO, Eduardo. Antologia. Rio de Janeiro: Agir, 1959, p. 9. 
meramente ao aspecto político-institucional. ${ }^{5}$ Embora houvesse por parte de Prado uma preocupação em apresentar uma série de fatos que pudessem comprovar a atuação dos Estados Unidos na sua política exterior com a América Latina (entenda-se como sinônimo de hispânica) e com o Brasil, Prado deixou clara sua visão de mundo acerca não somente do Brasil, mas também da América Latina, da Europa e, evidentemente, dos Estados Unidos.

Feitas algumas considerações preliminares, apresentarei, a seguir, parte do pensamento de Eduardo Prado, tal como proposto inicialmente.

\section{O Brasil e seus exteriores constitutivos: os Estados Unidos, a América Hispânica e a Europa}

Pensar o ser nacional nos remete para uma idéia de estabilidade, de permanência, de simetria e, portanto, de homogeneidade e identidade. Trata-se de um fundo de permanência diante de todas as mudanças, tal como sugere Baumer. ${ }^{6}$ Diante dessa mudança é que podemos conceber a idéia de não-ser como uma noção que não se confunde com o nada simplesmente como negação absoluta do ser, mas sim como um exterior constitutivo - o ser das outras nações - e também como interior transitivo, o que supostamente é um momento efêmero do ser que regula a sua primeira identificação com as outras nações para uma posterior diferenciação ontológica entre o "nós" e o "outro". Umut Ozkirimli sustenta que há um discurso nacionalista no qual a constituição do "caráter" nacional se define através não somente de um individualismo no qual a nação se reconhece como tal, mas também de um exterior constitutivo, 7 o qual vem a ser uma espécie de ser-nacional-do-outro que demarca a identidade nacional do outro, para dele se diferenciar.

Qual era o "caráter" do Brasil, sua condição permanente diante das outras nações? Que tipos de idéias sobre o Brasil foram produzidas/reproduzidas no pensamento de Eduardo Prado? Quais foram as imagens constituídas acerca do Brasil no seu pensamento, e como tais imagens foram negociadas na sua relação com outras nações e/ou continentes, como os Estados Unidos e a Europa, e mesmo com relação ao próprio Brasil que se tornava republicano?

5 Quando me refiro à República Brasileira, de modo específico, utilizo a expressão república com a letra inicial maiúscula. Ao fazer referência às formas republicanas de um modo geral, utilizo a expressão com letra inicial minúscula.

6 BAUMER, Franklin. O pensamento europeu moderno. Lisboa: Ed. 70, 1990, v. 1, p. 35.

7 ÖZKIRIMLI, Umut. Theories of nationalism. New York: St. Martin Press, 2000, p. 230. 
A preocupação com a questão nacional, com a tradição e com os aspectos mais amplos de que seria a cultura brasileira, foi continuamente afirmada por Prado. Embora houvesse, por parte do autor, uma preocupação imediata com os rumos da política externa brasileira diante do processo de americanização das relações internacionais, ${ }^{8}$ grande parte de seus argumentos relativos ao Brasil nos remete para uma suposta tradição que diferenciaria o Brasil dos Estados Unidos, e que, segundo o autor, seriam partes do ser nacional brasileiro. Tal referência a essa dimensão mais profunda fica clara no primeiro parágrafo de $A$ ilusão. De acordo com o autor:

Pensamos que é tempo de reagir contra a insanidade da absoluta confraternização que se pretende impor entre o Brasil e a grande república anglo-saxônia, de que nos achamos separados, não só pela grande distância, como pela raça, pela religião, pela índole, pela língua, pela história e pelas tradições de nosso povo. ${ }^{9}$

Falar numa tradição de nosso povo, bem como de diferenças de língua, de história e de índole como componentes que separavam o Brasil dos Estados Unidos já é um indicativo dos caminhos tomados por Prado para tornar mais plausíveis seus argumentos acerca do suposto equívoco do Brasil nos seus rumos políticos. No pensamento do autor, tal rumo era um desvio da essência, do ser brasileiro. A aproximação da República brasileira aos Estados Unidos não era uma ameaça somente para um Brasil imediato, um suposto Brasil efêmero, mas sim uma ameaça à identidade nacional do Brasil, uma intimidação ao seu ser, à sua condição permanente, eterna, transhistórica.

Seria pouco plausível, porém, partir do pressuposto de que essa idéia estivesse constituída de um modo unívoco, sem ambigüidades. Como sugere Hall, a identidade não assinala aquele núcleo estável do eu que passa, do início ao fim, sem qualquer mudança, por todas as vicissitudes da história. ${ }^{10}$ Nesse sentido, a idéia de identificação, concebida como uma construção, um processo nunca completado, uma articulação, vai ao encontro do que se entende ser a construção da própria identidade, algo que paira entre a "sombra e a substância"11, no pensamento de Prado.

8 A propósito desse processo e da relação dos intelectuais com ele, ver: SILVEIRA, Helder. Joaquim Nabuco e Oliveira Lima: faces de um paradigma ideológico da americanização nas relações internacionais do Brasil. Porto Alegre: EDIPUCRS, 2003.

9 PRADO, A ilusão..., p. 7.

10 HALL, Stuart. Quem precisa de identidade? In: SILVA, Tomaz Tadeu da (org.). Identidade e diferença: a perspectiva dos estudos culturais. Petrópolis: Vozes, 2000, p. 106.

11 BHABHA, Homi. O local da cultura. Belo Horizonte: Ed. da UFMG, 1998, p. 82. 
Qual seria esse exterior constitutivo mencionado, esse outro componente nacional que não se coadunaria com a tradição brasileira? Seria, em grande medida, não simplesmente a forma republicana per se, mas a violência, a corrupção, o laicismo e a ruína, qualidades que estavam relacionadas à forma republicana, especialmente em três circunstâncias: no caso hispano-americano, no caso norte-americano e, por fim, no Brasil pós-1889.

Prado entendia que as nações latino-americanas também haviam se corrompido quando se tornaram republicanas. O México era deprimente e opressor contra a Guatemala, que por sua vez mantinha guerras contra El Salvador, inimigo da Nicarágua. Para o autor, a história de todas essas nações era um "rio de sangue", um "contínuo morticínio". ${ }^{12}$ Prado estendia essa cadeia de ódios e rancores às repúblicas sul-americanas da mesma maneira, posto que para o autor, havia um ódio mortal entre Colômbia e Venezuela, Peru, Equador, Chile, Argentina e Uruguai. Nas próprias nações hispano-americanas, a fraternidade seria uma ilusão. Diante de todas essas repúblicas, havia uma primeira demarcação do "eles" que o diferenciaria do Brasil. De acordo com o autor:

Voltado para o sol que nasce, tendo, pela facilidade da viagem, os seus centros populosos mais perto da Europa que da maioria dos outros países americanos; separado deles pela diversidade da origem e da língua; nem o Brasil físico, nem o Brasil moral formam um sistema com aquelas nações. ${ }^{13}$

A América espanhola servia como uma fronteira para distanciar o Brasil, num sentido que consubstanciava a dimensão física com a moral. A força da negação dessa identidade foi ainda mais significativa no momento em que o autor optou por uma aproximação à Europa, como modo de afastar o Brasil da América Latina. Mas não era esse o principal exterior constitutivo da identidade nacional brasileira, haja vista que havia um outro ser nacional fundamental para essa demarcação da diferença: os Estados Unidos.

A história dos Estados Unidos praticamente se fundia com uma história de guerras, violências de todos os tipos, barbarismos e desrespeito a qualquer tipo de soberania, no pensamento de Prado. Apesar de uma visão um tanto quanto otimista dos pais fundadores da pátria americana, os quais teriam vivido num período histórico de pureza moral, em tempos de patriotismo e abnegação, Prado oscilava quanto à sua visão sobre os Estados Unidos. Nessa passagem, relativamente extensa, o autor apresentou

12 PRADO, A ilusão..., p. 8-9.

13 Ibid., p. 10. 
uma certa aproximação e o reconhecimento de uma suposta superioridade natural dos Estados Unidos:

A corrupção política e administrativa é a própria essência do funcionamento do governo americano. Os Estados Unidos são o país mais rico do mundo; rico pelas opulências naturais, pela sua enorme extensão, pela fertilidade do solo, pelos seus portos, suas baías, seus lagos, seus grandes rios navegáveis, suas minas incomparáveis. Povoado um solo destes pela raça saxônia, como poderia deixar este país de ser uma nação forte e poderosa? O solo mais rico do mundo, habitado pela raça mais enérgica da espécie humana - eis o que são os Estados Unidos. Aquele país é grande, mas não é por causa do seu governo. Ao amor-próprio de outras nações pobres ou, por outra, menos ricas em vantagens naturais do que os Estados Unidos e habitadas por indivíduos de raças menos enérgicas - repugna o confessar esta inferioridade. ${ }^{14}$

Nação forte e poderosa, mas decadente! Essa era a visão de Prado acerca da potência norte-americana. ${ }^{15}$ Sua aceitação da fatalidade física e racial, em prejuízo da história parece nos convencer de que o autor reconhecia a superioridade dos Estados Unidos. E o pior é que não se tratava da república - mas sim de fatores naturais que teriam levado o país àquela condição. Não posso deixar de reconhecer a força das teorias raciais de finais do século 19, haja vista que até os dias atuais a categoria raça, entendida enquanto dispositivo discursivo - e não biológico - ainda tem uma força significativa. ${ }^{16}$ Mas sua repulsa em confessar tal inferioridade já demonstrava, ao menos de um modo latente, um certo desconforto de Prado em relação à sua própria asserção.

Se isolada do conjunto do pensamento do autor acerca dos Estados Unidos, a citação acima pode nos encaminhar para um entendimento das idéias de Prado em que os fatores que teriam levado os Estados Unidos à corrupção, à decadência e a uma onda de violências cometidas contra os índios e contra os outros americanos não-saxônios no seu processo de expansão, seriam decorrentes do governo norte-americano, portanto, da república, mas não do seu ser. Mas seria essa, efetivamente, a visão do autor sobre o ser nacional dos Estados Unidos? Era essa ontologia da nação o componente regulador - através das categorias físicas e raciais que diferenciava o Brasil dos Estados Unidos?

14 PRADO, A ilusão..., p. 170

15 Uso essa expressão ciente de sua dimensão política, posto que geograficamente, a América do Norte não é circunscrita aos Estados Unidos.

16 Ver, a propósito dessa questão: HALL, Stuart. A identidade cultural na pósmodernidade. Rio de Janeiro: DP\&A, 2002. 
O próprio autor pareceu refutar a idéia de que houvesse uma superioridade norte-americana em relação ao Brasil - e aqui não somente no que diz respeito à república, mas uma diferenciação substancial, em que estariam envolvidos os próprios eus nacionais em seu âmago - ao atribuir aos norte-americanos certas qualidades negativas, como a violência física.

Se num determinado momento os males dos Estados Unidos estavam subordinados a uma república falseada - e não necessariamente por qualquer forma republicana -, em outros, o autor, metonimicamente, assumia a república como a essência do ser norte-americano e vice-versa - entenda-se essência como sinônimo de violência. Numa outra passagem, novamente um pouco extensa, Prado escreveu sobre a maneira como Brasil e Estados Unidos lidaram com a escravidão.

Cada forma de governo tem a sua tendência, e tem o seu modo peculiar de resolver os sucessivos problemas da história nacional. Tomemos, por exemplo, os Estados Unidos e o Brasil, ambos em frente do mesmo problema: a abolição da escravatura. Tiveram os Estados Unidos a sua solução genuinamente republicana e norte-americana, isto é, a solução pela violência, pela força, pelo grande fragor da guerra fratricida. Teve o Brasil uma solução genuinamente brasileira e monárquica, a solução que todos vimos, solução que excedeu os sonhos dos mais otimistas humanitários. Porventura deveremos envergonhar-nos da solução que soubemos e pudemos dar ao problema e sentir o não termos imitado os Estados Unidos também nesse ponto $?^{17}$

Parecia estar vingada aqui, a atribuição de uma suposta superioridade dos Estados Unidos, como se aquele reconhecimento reprimido da superioridade voltasse canalizado para uma outra esfera, que constituiria efetivamente o ser nacional ianque, o qual estabeleceria uma fronteira intransponível entre o "eles" do "nós". Afinal, a solução para a escravidão nos Estados Unidos era uma solução genuinamente republicana e norte-americana, contraposta à solução genuinamente brasileira e monárquica. $\mathrm{O}$ autor ainda reforçou tal idéia de uma essência do povo americano consubstanciada na violência ao narrar a história de uma pequena colônia americana (Estados Unidos) estabelecida no Brasil após a Guerra de Secessão nos Estados Unidos que, aproveitando-se da escravidão ainda vigente no Brasil, havia excedido "em ferocidade aos mais rudes e perversos atormentadores de escravos". ${ }^{18}$ Referindo-se aos Estados

17 PRADO, A ilusão..., p. 131-132.

18 Ibid., p. 174. 
Unidos, Prado afirmou que a civilização não era mensurada pelo aperfeiçoamento material, mas sim pelos seus níveis de elevação moral. Eduardo Prado entendia que o "verdadeiro termômetro da civilização de um povo é o respeito que ele tem pela vida humana e pela liberdade. Ora, os americanos têm pouco respeito pela vida humana. Não respeitam a vida de outrem e nem a própria". ${ }^{19}$ Ainda acrescentou o autor:

A vida de outrem é cousa de pouca consideração nos Estados Unidos. Os tribunais regulares matam juridicamente com freqüência, os assassinatos criminosos são vulgaríssimos, e os linchamentos crescem em número todos os dias. Tudo isto são formas acentuadas de desprezo pela vida humana. ${ }^{20}$

Onde estava a superioridade americana, afirmada pelo próprio Prado num outro momento? Prado reconhecia uma força material significativa dos Estados Unidos, talvez insuperável, mas não era esse seu padrão civilizacional. $\mathrm{O}$ que era o ser brasileiro diante desse exterior constitutivo, sua substância, portanto, seu interior constitutivo, o Brasil efetivo?

Para o escritor, o espírito americano era um espírito de violência; o espírito latino, transmitido aos brasileiros, era, por sua vez, um espírito jurídico que, apesar do bacharelismo, conservava sempre um certo respeito pela vida humana e pela liberdade. ${ }^{21}$ No pensamento de Prado, a identidade nacional não podia emanar de qualquer exterioridade, posto que, para o autor, as sociedades deviam ser regidas por leis saídas de sua raça, de sua história, do seu caráter, do seu desenvolvimento natural. ${ }^{22}$ Qualquer cópia, nesse sentido, seria um deslize de sua essência. Neste caso, poderíamos perguntar: mas a monarquia, não seria, ela própria, uma instituição externa ao Brasil?

Tentando seguir os rumos do autor, aqui haveria uma diferença entre a imitação e a encarnação de leis que seriam naturalmente assimiladas. É evidente que tal naturalização como estratégia retórica poderia ser facilmente refutada, afinal, por que naturalizar a monarquia, como se esta fosse essencialmente brasileira, e historicizar a república, como algo exógeno às tradições do Brasil? É possível afirmar, nesse esforço interpretativo do pensamento do autor, que a identidade nacional, esse sentimento comum de pertencimento, não tem um respaldo empírico para fundamentá-lo, e

19 Ibid., p. 173.

20 Ibid., p. 173-174.

21 Ibid., p. 175.

22 Ibid., p. 45. 
que ele se baseia, em grande escala, num ato de fé, e não de razão. Fazia parte das crenças e valores de Prado a idéia de que a monarquia era uma instituição efetivamente brasileira e de que o Brasil era essencialmente monárquico.

Por outro lado, o que torna o pensamento de Prado mais interessante é que o autor não buscou seu modelo de monarquia na Europa. ${ }^{23}$ Apesar do autor perceber na Europa um refúgio para a liberdade, desaparecida na América, não era a Europa o modelo preconizado pelo autor. A Europa, de certo modo, encantava Prado, e muitos dos países que a compõem eram admirados pelo autor, como a Inglaterra, por exemplo. Mas é importante reiterar: para Prado, tratava-se apenas de retornar ao que o Brasil era. Ser o que o Brasil era, para continuar sendo alguma coisa. Era o Brasil o seu próprio modelo de Brasil.

\section{A República Brasileira: interior transitivo frente ao ser da nação}

Se havia um Brasil que servia de modelo para o Brasil, havia, evidentemente, mais de um Brasil. Portanto, o cânone não era o Brasil efêmero, que se constituía, para continuar jogando com a idéia de exterioridade/interioridade, num interior transitivo. Se a violência era o ser dos Estados Unidos, um dos exteriores constitutivos do Brasil repudiados por Prado, mas que regulava as fronteiras entre o sagrado e o profano, entre o ser e o não-ser do Brasil, o Brasil monárquico, personificado na figura de D. Pedro II, de índole pacífica, libertadora e desinteressada era a natureza do Brasil, o próprio Brasil fundado dentro de uma temporalidade pedagógica ${ }^{24}$ que expulsava o tempo através da afirmação de uma eternidade confundida com as instituições monárquicas. A República significava para Prado a decadência, um presente sem precedente no passado, como se todo o horizonte de suas expectativas, para usar uma expressão de Koselleck, ${ }^{25}$ não tivesse qualquer respaldo no campo de experiências da monarquia. Esse hiato era inaceitável para Prado. E a República representava essa fissura que levaria o

23 Em algumas passagens, Prado refere-se às monarquias da Europa como velhas e carcomidas (ibid., p. 37).

24 BHABHA, op. cit., p. 210. Nessa mesma página, Bhabha apresenta suas idéias do que seja um tempo pedagógico, que funda sua autoridade numa narrativa substancializada da nação, e o tempo performativo, que evoca e rasura tal temporalidade autogerativa.

25 KOSELLECK, Reinhardt. Futuro pasado: para una semántica de los tiempos históricos. Barcelona: Paidós, 1993. 
Brasil ao abismo. A propósito dessas metáforas, Prado, numa clara manifestação pró-monárquica, assim aludiu à república: "pergunto eu a todo o mundo: quem chega bem à beira de um precipício e sente já a vertigem da queda fatal, o que instintivamente faz para não perecer? Recua e retrocede". ${ }^{26}$

Se a República se constituía em um regime transitivo, portanto, subordinado a uma certa historicidade que lhe conferia uma dimensão finita, sobretudo por causa de seu desvio dos rumos civilizacionais, afinal, Prado reivindicava como ideal, o "restabelecimento da civilização brasileira, com a volta à liberdade e à tolerância, bens supremos de que nos despojamos e que os nossos filhos saberão reconquistar", ${ }^{27}$ o retorno à monarquia seria apenas uma questão de tempo, uma história do futuro que religaria a esperança com as experiências.

\section{A questão da ideologia}

Feito esse esforço interpretativo do pensamento de Eduardo Prado, farei algumas aproximações reflexivas sobre a questão da ideologia. Em que medida o pensamento de Eduardo Prado seria ideológico? Podemos lançar mão de tal categoria para pensar o pensamento de um intelectual, mesmo que ele não tenha conseguido fornecer uma visão homogênea de seu próprio pensamento, para fins de persuasão?

A obra A ilusão americana, bem como o pensamento de Prado, de um modo geral, se orientaram para uma crítica contundente da república implantada no Brasil e na preconização de um retorno à monarquia. Evidentemente, para sabermos dos efeitos de seu pensamento na sociedade brasileira de fins do século XIX, haveria a necessidade de elaborar um estudo da recepção de sua obra, o que envolve uma análise complexa dos processos de codificação e decodificação da própria ação comunicativa, proposta teórica que transcende os escopos desse artigo. De volta à questão da ideologia, é mister esboçar uma discussão teórica acerca de alguns de seus pressupostos. Isso não implica adentrar no campo da história do conceito, o que já foi realizado por diversos autores ${ }^{28}$, mas sim apresentar uma abordagem epistemológica de tal concepção.

6 PRADO, Antologia, p. 49.

7 Ibid., p. 57.

28 THOMPSON, John. Ideologia e cultura moderna. Petrópolis: Vozes, 1995; LÖWY, Michael. Ideologias e ciência social. São Paulo: Cortez, 1999; MANNHEIM, Karl. Ideologia e utopia. Rio de Janeiro: Zahar, 1972. 
É importante mencionar, nesse sentido, que não postulo o pressuposto da ideologia como falsa consciência, como um instrumento criado pelas classes (ou grupos étnicos, gêneros, estadosnação) dominantes que serviria para obscurecer a realidade. Estou de acordo com Morin, quando afirma:

Uma sociedade produz uma ideologia, uma idéia, mas não o sinal de que ela seja verdadeira ou falsa... Mesmo as condições mais singulares, mais localizadas, mais particulares, mais históricas da emergência de uma idéia, de uma teoria, não são prova da sua veracidade - evidentemente - nem da sua falsidade. Existe um princípio de incerteza sobre o fundo de verdade. É o problema da epistemologia, da dialética e da verdade. ${ }^{29}$

Ao chamar a atenção para o conceito de ideologia, não tenho a pretensão de aplicá-lo a um pensamento a fim de determinar seus níveis de comprometimento com uma idéia de realidade tomada como um ponto de partida natural, dado de antemão antes de qualquer relação subjetiva ou intersubjetiva. Não interessa aqui saber se Eduardo Prado falava a verdade ou não. A assunção de tais pressupostos seria apenas um retorno ingênuo a um realismo metafísico.

Por outro lado, se afirmo uma idéia de ideologia em que esta seja concebida como um conjunto de representações que, em circunstâncias particulares, serve para estabelecer e sustentar relações de dominação, quaisquer que elas sejam, ${ }^{30}$ tal concepção eliminaria o peso epistemológico da dicotomia verdade/falsidade. Mas, pergunto: o pensamento de Eduardo Prado tinha como pretensão sustentar relações de dominação? Dominar seu público leitor para convencê-lo de que a ordem social monárquica era a correta e não a republicana? Havia, em seu pensamento, um esforço de convencer seus leitores da legitimidade da monarquia, mas tal estratégia retórica era apenas parte de uma visão de mundo mais ampla que não se esgotava na construção de um sentido para fins de dominação e subordinação, mesmo porque uma visão de mundo não significa, necessariamente, que ela esteja vinculada a relações de dominação e subordinação.

Não obstante, no pensamento de Eduardo Prado havia um jogo constante de lembranças e esquecimentos que constituíram a própria memória histórica que ele pretendeu legitimar. ${ }^{31}$ Memória

29 MORIN, Edgar. A epistemologia da complexidade. In: MORIN, Edgar et al. A inteligência da complexidade. São Paulo: Petrópolis, 2000, p. 68-69.

30 THOMPSON, op. cit., p. 76.

31 POLLAK, Michael. Memória, esquecimento, silêncio. Estudos Históricos, Rio de Janeiro, v. 2, n. 3, p. 3-15, 1989. 
que se substancializava no seu esforço de narrar a história e os rumos de sua nação. Nessa construção, houve a delimitação de centros e margens, de um mesmo (Brasil monárquico), e de outros (Europa, América espanhola, Estados Unidos e Brasil republicano). Ademais, havia a idéia de um Estado-nação afirmado e de sujeitos que o constituíam, uma seleção de sujeitos - aqueles que fazem a história -, mesmo diante da afirmação de idéias naturalistas, como organismo social, para se referir à sociedade. É difícil dissociar a produção dessa memória substancializada sem recorrer às relações de poder em uma dada sociedade, afinal, esse jogo da memória está profundamente relacionado a uma idéia de subordinação ou autonomia de sujeitos (individuais e coletivos) que se inscrevem na construção de uma memória particular que se pretendia universalizar, bem como de uma situação histórica peculiar que se desejava eternizar. Em ambos os casos, é bastante sugestiva a idéia de que Prado se utilizou de certas estratégias concebidas como modos de operação da ideologia ${ }^{32}$, para efeitos retóricos.

Há ainda, uma outra noção de ideologia que parece pertinente para o caso em estudo. A ideologia como um conjunto de pensamentos, concepções, crenças, valores que serviriam para perpetuar uma determinada ordem social estabelecida - com toda a sua complexidade -, ou seja, qualquer visão de mundo que serviria para a manutenção de uma estrutura social. ${ }^{33}$ Como seu contraponto, grosso modo, haveria a utopia, ou seja, idéias, representações, teorias que aspiram a uma outra ordem, não existente e que têm, portanto, uma dimensão crítica ou de negação da ordem social existente, orientando-se para a sua ruptura. ${ }^{34}$ Utopia enquanto insatisfação com uma determinada realidade constituída, o que pressupõe a construção de uma outra realidade, mesmo que essa realidade que se almeja edificar seja um retorno ao passado.

Colocadas as pressuposições desse modo, o pensamento de Eduardo Prado não seria ideológico, mas sim utópico, afinal, suas idéias tinham um teor subversivo - sua obra $A$ ilusão americana, como já mencionado, foi imediatamente censurada após a sua publicação, em 1893. Mesmo que a ordem social monárquica não existisse mais, tratava-se de orientar as gerações futuras para o retorno da monarquia. Nas suas palavras: "trabalha, pois, pela justiça e pela liberdade uma força que nenhum decreto pode agrilhoar e que nenhuma força ameaça pode deter. Essa força é o futuro"..$^{35}$

32 THOMPSON, op. cit., p. 81.

33 LÖWY, op. cit., p. 13.

34 Ibid.

35 PRADO, Antologia, p. 57. Ver a citação correspondente à nota 24. 
A ordem preconizada por Prado nos remete novamente para a equação entre raízes e opções, ou melhor, das raízes como opção de futuro para o Brasil. ${ }^{36}$ Não poderia haver expectativas com a República, posto que ela rompia com o campo das experiências, com a história, confundida com a pátria, com a nação. ${ }^{37}$ Retomar esse equilíbrio em que o campo de experiências era o horizonte das expectativas do Brasil - o seu futuro -, era a dimensão utópica do pensamento de Prado, contraposta às ideologias, que serviriam para legitimar a República. Portanto, o pensamento de Eduardo Prado estaria mais próximo da utopia, do que propriamente da ideologia, a não ser num sentido - intencional ou não - de construção de certas estratégias de persuasão que poderiam levar a relações de poder, de assimetria entre Prado e seus interlocutores - o sentido negativo proposto por Thompson.

Em ambos os casos, parece-me necessário ter um certo cuidado para não cristalizar e homogeneizar o pensamento do autor, posto que a denúncia perpetrada por Prado foi também um jogo de articulações e posições das identidades, em que as idéias circularam, foram resignificadas e rearranjadas de modos distintos, sem que elas se fechassem e se fixassem como ideológicas ou utópicas. Entendo que há uma certa plausibilidade em trabalhar com as categorias de ideologia e utopia, sobretudo nas obras de um autor cujo pensamento manteve, na maior parte das vezes, um teor fortemente político, de denúncia do regime republicano que se consolidava no Brasil. O que parece escapar dessas categorias é o que escapa, em certo sentido, da sociologia do conhecimento: a historicidade do pensamento. Não uma historicidade subordinada às lutas de classes, de gêneros e/ou de Estadosnação, mas a própria mobilidade do pensamento acerca da identidade nacional, de seu componente performativo em que a diferença é constantemente posta no jogo das identificações. ${ }^{38}$

36 Tal dicotomia é muito bem trabalhada por Santos, para quem o pensamento das raízes é o pensamento de tudo aquilo que dá segurança e consistência; o pensamento das opções é variável, efêmero, substituível, possível e indeterminado a partir das raízes. Ver: SANTOS, Boaventura de Sousa. A queda do Angelus Novus: para além da equação moderna entre raízes e opções. Revista Crítica de Ciências Sociais, Lisboa, n. 45, p. 9, maio 1996.

37 "O desrespeito que nos desorganiza, nos avassala e nos barbariza é, até certo ponto, o resultado da nossa ruptura com o passado, dessa lamentável emancipação da sua autoridade" (PRADO, Antologia..., p. 70).

38 BHABHA, op. cit., p. 210. 
Na produção de seus significados, Prado apresentou uma série de idéias, valores, crenças, que se encontravam sedimentadas em seu pensamento - como o mito da pacificidade do brasileiro -, as quais eram articuladas a idéias que circulavam pelo mundo de fins do século XIX, como as teorias raciais e seu princípio de questionamento por parte de alguns intelectuais, o positivismo e sua reação contra ele, bem como as reações contra o naturalismo, a afirmação do pensamento nacionalista e de uma identidade nacional, tarefa que já ocupava os intelectuais brasileiros pelo menos desde 1838, com a criação do Instituto Histórico e Geográfico Brasileiro. É importante ressaltar que não quero, com isso, afirmar que Eduardo Prado tenha se antecipado ao seu tempo, que ele tenha sido um intelectual extemporâneo; pelo contrário, o pensamento de Prado encarna a própria mobilidade histórica de um período cujas cosmovisões foram fortemente marcadas pelo jogo complexo da mudança histórica, tanto num nível global, em que o pensamento de fins do século cada vez mais se orientava em torno do devir e da incerteza ${ }^{39}$, como num sentido mais delimitado, das querelas que envolviam o próprio Brasil que se tornava republicano. Sem se fechar numa síntese, o pensamento de Prado parece ter se articulado nesses pólos, muitas vezes contraditórios entre si, mas que estavam profundamente ligados à sua tentativa de construir uma identidade nacional cujo modo de ser era o próprio modo de ser monárquico do Brasil.

39 BAUMER, Franklin. O pensamento europeu moderno. Lisboa: Ed. 70, 1990, v. 2, p. 132. 